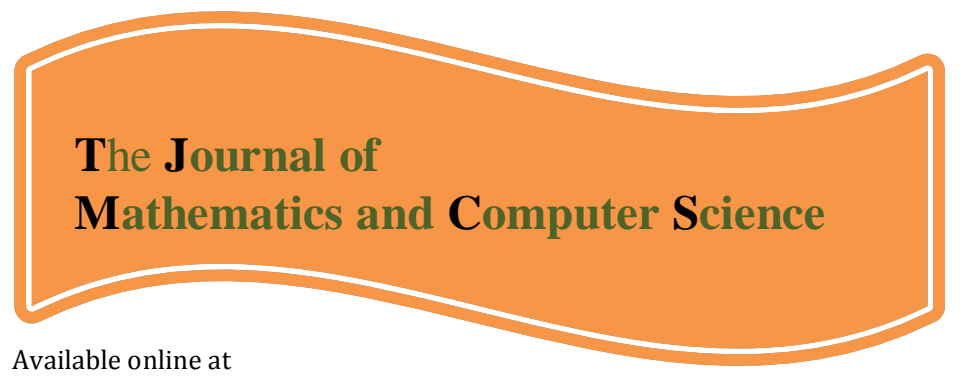

http://www.TJMCS.com

The Journal of Mathematics and Computer Science Vol .2 No.4 (2011) 667-671

\title{
A numerical algorithm for solving nonlinear fuzzy differential equations
}

\author{
M. Rostami1', M. Kianpour², E. bashardoust ${ }^{3}$ \\ Department of Mathematics, Naragh Branch, Islamic Azad University, Naragh, Iran \\ Department of Mathematics, Faculty of Sciences, University of Guilan, Rasht, Iran \\ 1m.rostami@kiau.ac.ir \\ _2kianpour@quilan.ac.ir \\ 33bashardoust-iman@yahoo.com
}

Received: August 2010, Revised: November 2010

Online Publication: January 2011

\begin{abstract}
In this paper, we propose a numerical algorithm based on Runge-Kutta methods to and solution of nonlinear fuzzy differential equations (FDEs) such that it solution satisffes solution found via differential inclusions. Our interpretation of the FDEs is a family of fuzzy differential inclusions. The method is illustrated by some examples.
\end{abstract}

Keywords: Nonlinear Fuzzy differential equations, Fuzzy differential inclusions, H-difference, Runge-Kutta methods.

\section{Introduction}

Fuzzy set theory is an approach for modeling of uncertainty which is existence in environment. This theory has application in the golden mean [1], quantum optics and gravity [2].

Particularly, the concept of differentiability of fuzzy function is important in many applications. This concept is initially introduced based on Zadeh's extension principle, then further research were done by Puri and Ralescu [3].

In many papers, using of Hakuhara derivative to find solution of FDEs. It is shown that the solution of many FDEs hasn't existed. Thereby a generalization derivative was given for fuzzy mappings enlarging 


\section{Rostami, M. Kianpour, E. bashardoust/ TJMCS Vol .2 №.4 (2011) 667-671}

the class of differentiable fuzzy mappings by Bede and Gal in [4,5], and Chalco-Cano and Flores use from this concept to

solve FDEs in $[6,7,8]$. For solving the FDE, $x^{\prime}(t)=f(t, x(t)), x(0)=x_{0}$, is shown that when $g(x)$ is nondecreasing or nonincreasing the solution of FDEs is exists.

In this paper we consider this problem when $\mathrm{g}(\mathrm{x})$ is no ones. We proposed an algorhtim that tries to find the solution.

This paper has been organized as follows : Section 2 contains the basic material to be used in the rest of the article, in section 3 we shall see that this definition of fuzzy lateral H-derivative leads us to interpret a FDE in two different forms, generating new solutions for FDE, in section 4,we present a numerical procedure for solving the fuzzy initial value problem $x^{\prime}(t)=f(t, x(t)), x(0)=x_{0}$, when $f$ is decreasing(increasing) or not decreasing(not increasing). Finally, numerical algorithms of calculating approximates to these solutions where designed.

\section{Basic concepts}

Let $X$ be a Banach space. We denote by $K(X)$ the family of all nonempty compact subsets of $X$. If $\mathrm{A}, \mathrm{B} \in \mathrm{K}(\mathrm{X})$ and $\lambda \in \mathrm{R}$, then the operations of addition and scalar multiplication are defined as, $\mathrm{A}+\mathrm{B}=\{\mathrm{a}+\mathrm{b} \mid \mathrm{a} \in \mathrm{A}, \mathrm{b} \in \mathrm{B}\}, \lambda \mathrm{A}=\{\lambda \mathrm{a} \mid \mathrm{a} \in \mathrm{A}\}$.

A fuzzy set $u$ on a universe set $X$ is a mapping $u: X \rightarrow[0,1]$. Then $u(x)$ is interpreted as the degree of membership of a element $\mathrm{x}$ in the fuzzy set $\mathrm{u}$ for each $\mathrm{x} \in \mathrm{X}$.

If $X$ is a Banach space and $u$ is a fuzzy set on $X$, We define $[u]^{\alpha}=\{x \in X \mid u(x \leq \alpha$ the $\alpha$-level of $u$, for $0<\alpha \leq 1$. For $\alpha=0$ the support of $u$ is defined as $[u]^{0}=\sup p(u)=\overline{\{x \in X \mid u(x)>0\}}$, where $\bar{A}$ denotes the closure of $\mathrm{A} \subset \mathrm{X}$.

A fuzzy set $\mathrm{u}$ on $\mathrm{X}$ is called compact if $[\mathrm{u}]^{\alpha} \in \mathrm{K}(\mathrm{X}), \forall \alpha \in[0,1]$. Also, $\mathrm{u}$ is called convex if $[\mathrm{u}]^{\alpha}$ is a convex set for all $\alpha \in[0,1]$. We will denote by $F(X)$ the space of all compact and convex fuzzy sets on $X$. If $\mathrm{u} \in \mathrm{F}(\mathrm{R})$ be, then $\mathrm{u}$ is called a fuzzy interval and the $\$ \backslash$ alpha-level set $[\mathrm{u}]^{\alpha}$ is a nonempty compact interval for all $\alpha \in[0,1]$.

If $\mathrm{u}, \mathrm{v} \in \mathrm{F}\left(\mathrm{R}^{\mathrm{n}}\right)$ and $\lambda \in \mathrm{R}$, then the following properties are true :

$[\mathrm{u}+\mathrm{v}]^{\alpha}=[\mathrm{u}]^{\alpha}+[\mathrm{v}]^{\alpha},[\lambda \mathrm{u}]^{\alpha}=\lambda[\mathrm{u}]^{\alpha}, \forall \alpha \in[0,1]$.

Also, the Hausdorff metric $H$ on $\mathrm{K}\left(\mathrm{R}^{\mathrm{n}}\right)$ can be extended to $\mathrm{F}\left(\mathrm{R}^{\mathrm{n}}\right)$ by the following definition

$\mathrm{D}(\mathrm{u}, \mathrm{v})=\sup _{\alpha \in[0,1]} \mathrm{H}\left([\mathrm{u}]^{\alpha},[\mathrm{v}]^{\alpha}\right), \forall \mathrm{u}, \mathrm{v} \in \mathrm{F}\left(\mathrm{R}^{\mathrm{n}}\right)$.

\section{Fuzzy differential equations}

Definition 1. Let $u, v \in F\left(R^{n}\right)$ be. If there exists $w \in F\left(R^{n}\right)$ such that $u=v+w$, then $w$ is called the Hdifference of $u$ and $v$ and denoted by $u \Theta v$.

Definition 2. Let be $F:[0, T] \rightarrow F\left(R^{n}\right)$, and $t_{0} \in[0, T]$, we say that $F$ is differentiable at $t_{0}$ if :

(I): It exists an element $\mathrm{F}^{\prime}\left(\mathrm{t}_{0}\right) \in \mathrm{F}\left(\mathrm{R}^{\mathrm{n}}\right)$ such that, for all $\mathrm{h}>0$ suffciently near to 0 , there are $\mathrm{F}\left(\mathrm{t}_{0}+\mathrm{h}\right) \Theta \mathrm{F}\left(\mathrm{t}_{0}\right), \mathrm{F}\left(\mathrm{t}_{0}\right) \Theta \quad \mathrm{F}\left(\mathrm{t}_{0}-\mathrm{h}\right)$ and the limits (in D-metric)

$$
\lim _{\mathrm{h} \rightarrow 0^{+}} \frac{\mathrm{F}\left(\mathrm{t}_{0}+\mathrm{h}\right) \theta \mathrm{F}\left(\mathrm{t}_{0}\right)}{\mathrm{h}}=\lim _{\mathrm{h} \rightarrow 0^{+}} \frac{\mathrm{F}\left(\mathrm{t}_{0}\right) \theta \mathrm{F}\left(\mathrm{t}_{0}-\mathrm{h}\right)}{\mathrm{h}}=\mathrm{F}^{\prime}\left(\mathrm{t}_{0}\right)
$$

(II): It exists an element $\mathrm{F}^{\prime}\left(\mathrm{t}_{0}\right) \in \mathrm{F}\left(\mathrm{R}^{\mathrm{n}}\right)$ such that, for all $\mathrm{h}<0$ suffciently near to 0 , there are $\mathrm{F}\left(\mathrm{t}_{0}+\mathrm{h}\right) \Theta \mathrm{F}\left(\mathrm{t}_{0}\right), \mathrm{F}\left(\mathrm{t}_{0}\right) \Theta \quad \mathrm{F}\left(\mathrm{t}_{0}-\mathrm{h}\right)$ and the limits (in D-metric) 


$$
\lim _{\mathrm{h} \rightarrow 0^{-}} \frac{\mathrm{F}\left(\mathrm{t}_{0}+\mathrm{h}\right) \theta \mathrm{F}\left(\mathrm{t}_{0}\right)}{\mathrm{h}}=\lim _{\mathrm{h} \rightarrow 0^{-}} \frac{\mathrm{F}\left(\mathrm{t}_{0}\right) \theta \mathrm{F}\left(\mathrm{t}_{0}-\mathrm{h}\right)}{\mathrm{h}}=\mathrm{F}^{\prime}\left(\mathrm{t}_{0}\right)
$$

Theorem 1. Let $F:[0, T] \rightarrow F(R)$ be a function and denote $[F(t)]^{\alpha}=\left[f_{\alpha}(t), g_{\alpha}(t)\right]$, for each $\alpha \in[0,1]$. Then, (1) If $F$ is differentiable in the first form (I), then $f_{\alpha}$ and $g_{\alpha}$ are differentiable functions and

$$
\left[\mathrm{F}^{\prime}(\mathrm{t})\right]^{\alpha}=\left[\mathrm{f}_{\alpha}^{\prime}(\mathrm{t}), \mathrm{g}_{\alpha}^{\prime}(\mathrm{t})\right]
$$

(2) If $F$ is differentiable in the second form (II), then $f_{\alpha}$ and $g_{\alpha}$ are differentiable functions and

$$
\left[\mathrm{F}^{\prime}(\mathrm{t})\right]^{\alpha}=\left[\mathrm{g}_{\alpha}^{\prime}(\mathrm{t}), \mathrm{f}_{\alpha}^{\prime}(\mathrm{t})\right]
$$

Proof. see demonstration of Theorem 5 in [6].

Let $\mathrm{q}:[0, \mathrm{~T}] \times \mathrm{F}(\mathrm{R}) \rightarrow \mathrm{F}(\mathrm{R})$ be a function. consider the following fuzzy differential equation:

$$
\left\{\begin{array}{l}
X^{\prime}(t)=q(t, X(t)) \\
X(0)=X_{0}
\end{array}\right.
$$

Let $[X(t)]^{\alpha}=\left[f_{\alpha}(t), g_{\alpha}(t)\right],\left[X_{0}\right]^{\alpha}=\left[f_{\alpha}^{0}, g_{\alpha}^{0}\right]$ and $[q(t, X(t))]^{\alpha}=\left[k_{\alpha}\left(t, f_{\alpha}(t), g_{\alpha}(t)\right), 1_{\alpha}\left(t, f_{\alpha}(t), g_{\alpha}(t)\right)\right]$.

If $\mathrm{X}(\mathrm{t})$ is differentiable in the first form $(\mathrm{I})$, then from (3) we have $\left[\mathrm{X}^{\prime}(\mathrm{t})\right]^{\alpha}=\left[\mathrm{f}_{\alpha}^{\prime}(\mathrm{t}), \mathrm{g}_{\alpha}^{\prime}(\mathrm{t})\right]$ and the problem (5) is changed to:

$$
\begin{cases}\mathrm{f}_{\alpha}^{\prime}(\mathrm{t})=\mathrm{k}_{\alpha}\left(\mathrm{t}, \mathrm{f}_{\alpha}(\mathrm{t}), \mathrm{g}_{\alpha}(\mathrm{t})\right) & \mathrm{f}_{\alpha}(0)=\mathrm{f}_{\alpha}^{0} \\ \mathrm{~g}_{\alpha}^{\prime}(\mathrm{t})=\mathrm{l}_{\alpha}\left(\mathrm{t}, \mathrm{f}_{\alpha}(\mathrm{t}), \mathrm{g}_{\alpha}(\mathrm{t})\right) & \mathrm{g}_{\alpha}(0)=\mathrm{g}_{\alpha}^{0}\end{cases}
$$

and if $X(t)$ is differentiable in the second form (II), then from (4) we have $\left[X^{\prime}(t)\right]^{\alpha}=\left[g_{\alpha}^{\prime}(t), f_{\alpha}^{\prime}(t)\right]$ and the problem (5) is changed to:

$$
\left\{\begin{array}{lc}
\mathrm{f}_{\alpha}^{\prime}(\mathrm{t})=\mathrm{l}_{\alpha}\left(\mathrm{t}, \mathrm{f}_{\alpha}(\mathrm{t}), \mathrm{g}_{\alpha}(\mathrm{t})\right) & \mathrm{f}_{\alpha}(0)=\mathrm{f}_{\alpha}^{0} \\
\mathrm{~g}_{\alpha}^{\prime}(\mathrm{t})=\mathrm{k}_{\alpha}\left(\mathrm{t}, \mathrm{f}_{\alpha}(\mathrm{t}), \mathrm{g}_{\alpha}(\mathrm{t})\right) & \mathrm{g}_{\alpha}(0)=\mathrm{g}_{\alpha}^{0}
\end{array}\right.
$$

\section{Fuzzy differential inclusions}

In this section the FDE is interpret as a fuzzy differential inclusion. In the FDE (5), $q:[0, T] \times F(R) \rightarrow F(R)$ is

obtained by Zadeh's extension principle from a differentiable function, $q s:[0, T] \times R \rightarrow R$.

We interpret the fuzzy initial value problem (5) as family of differential inclusions

$$
\begin{aligned}
& \mathrm{y}_{\alpha}^{\prime}(\mathrm{t}) \in\left[\mathrm{q}\left(\mathrm{t}, \mathrm{y}_{\alpha}(\mathrm{t})\right)\right]^{\alpha}, \quad \mathrm{y}_{\alpha}(0) \in\left[\mathrm{X}_{0}\right]^{\alpha}, \quad 0 \leq \alpha \leq 1 \\
& \mathrm{y}_{\alpha}^{\prime}(\mathrm{t})=\mathrm{qs}\left(\mathrm{t}, \mathrm{y}_{\alpha}(\mathrm{t})\right), \quad \mathrm{y}_{\alpha}(0) \in\left[\mathrm{X}_{0}\right]^{\alpha}, \quad 0 \leq \alpha \leq 1
\end{aligned}
$$

The attainable sets is defined as $A_{\alpha}(t)=\left\{y_{\alpha}(t) \mid y_{\alpha}(t)\right.$ is a solution of (9) $\}$. A more complete account can be found in $[14,21,23]$.

Theorem 2. Let $\mathrm{X}_{0} \in \mathrm{F}\left(\mathrm{R}^{\mathrm{n}}\right)$ and let $\Omega$ be an open subset of $\mathrm{R} \times \mathrm{R}^{\mathrm{n}}$ containing $\{0\} \times \operatorname{supp}\left(\mathrm{X}_{0}\right)$. Suppose that $\mathrm{q}: \Omega \rightarrow \mathrm{F}\left(\mathrm{R}^{\mathrm{n}}\right)$ is use and compact. Let the boundedness assumption hold, for all $\mathrm{x}_{0} \in \operatorname{supp}\left(\mathrm{X}_{0}\right)$ and the inclusion

$$
\mathrm{y}^{\prime}(\mathrm{t}) \in[\mathrm{q}(\mathrm{t}, \mathrm{y}(\mathrm{t}))]^{\alpha=0}, \quad \mathrm{y}(0) \in \operatorname{supp}\left(\mathrm{X}_{0}\right)
$$

Then, the attainable sets $A_{\alpha}(t)$ of the family of inclusions (9) are the level sets of a fuzzy set $A(t)$, $[21,23]$.

Theorem 3. Let $U$ be an open set in $R^{n}$ and $X_{0} \in F\left(R^{n}\right)$. Suppose that qs is continuous, that for each $\mathrm{c} \in \mathrm{U}$ there exists one unique solution $\mathrm{x}(\cdot, \mathrm{c})$ of problem $(9)$ and that $\mathrm{x}(\mathrm{t}, \cdot)$ is continuous in $\mathrm{U}$ for each $\mathrm{t} \in[0, \mathrm{~T}]$. Then :

If qs is nondecreasing with respect to the second argument then, using the first form (I), the fuzzy solution of (5) and the solution via differential inclusions are identical. 
If qs is nonincreasing with respect to the second argument then, using the derivative in the second form (II), the fuzzy solution of (5) and the solution via differential inclusions are identical.

Proof. see demonstration of Theorem 7,8 in [6].

\section{Numerical Algorithm}

Let $f_{\alpha}, g_{\alpha}$ be as mention in Theorem 1 , denote $d q(t, x)=\frac{\partial}{\partial x} q s(t, x)$.

In the following we proposed an algorithm which based on second order Runge-Kutta method. Algorithm .

1. choose $\mathrm{m}, \mathrm{n}$ two integer number. let $\mathrm{h}_{\alpha}=\frac{1}{\mathrm{~m}}, \mathrm{~h}_{\mathrm{t}}=\frac{\mathrm{T}}{\mathrm{n}}$.

2. Repeat steps $3-12$ for $i=0, \ldots, m$ :

3. $\alpha=(\mathrm{m}-\mathrm{i}) \mathrm{h}_{\alpha}, \mathrm{y}_{\alpha}(0)=\left[\mathrm{y}_{1 \alpha}(0), \mathrm{y}_{2 \alpha}(0)\right]=\left[\mathrm{X}_{0}\right]^{\alpha}$.

4. Repeat steps $5-12$ for $\mathrm{j}=1, \ldots, \mathrm{n}$ :

5. $\mathrm{t}=\mathrm{jh} \mathrm{t}_{\mathrm{t}}$.

6. if $\mathrm{dq}\left(\mathrm{t}, \mathrm{y}_{1}(\mathrm{t})\right)>0$, then repeat steps $7-9$, else repeat $10-12$.

7. $\mathrm{k}_{1}=\mathrm{h}_{\mathrm{t}} \mathrm{k}_{\alpha}\left(\mathrm{t}, \mathrm{y}_{1 \alpha}(\mathrm{t}), \mathrm{y}_{2 \alpha}(\mathrm{t})\right), \mathrm{l}_{1}=\mathrm{h}_{\mathrm{t}} \mathrm{l}_{\alpha}\left(\mathrm{t}, \mathrm{y}_{1 \alpha}(\mathrm{t}), \mathrm{y}_{2 \alpha}(\mathrm{t})\right)$.

8. $\mathrm{k}_{2}=\mathrm{h}_{\mathrm{t}} \mathrm{k}_{\alpha}\left(\mathrm{t}+\mathrm{h}_{\mathrm{t}}, \mathrm{y}_{1 \alpha}(\mathrm{t})+\mathrm{k}_{1}, \mathrm{y}_{2 \alpha}(\mathrm{t})+\mathrm{l}_{1}\right), \mathrm{l}_{2}=\mathrm{h}_{\mathrm{t}} \mathrm{l}_{\alpha}\left(\mathrm{t}+\mathrm{h}_{\mathrm{t}}, \mathrm{y}_{1 \alpha}(\mathrm{t})+\mathrm{k}_{1}, \mathrm{y}_{2 \alpha}(\mathrm{t})+\mathrm{l}_{1}\right)$.

9. $\mathrm{y}_{1 \alpha}\left(\mathrm{t}+\mathrm{h}_{\mathrm{t}}\right)=\mathrm{y}_{1 \alpha}(\mathrm{t})+\frac{1}{2}\left(\mathrm{k}_{1}+\mathrm{k}_{2}\right), \mathrm{y}_{2 \alpha}\left(\mathrm{t}+\mathrm{h}_{\mathrm{t}}\right)=\mathrm{y}_{2 \alpha}(\mathrm{t})+\frac{1}{2}\left(\mathrm{l}_{1}+\mathrm{l}_{2}\right)$.

10. $\mathrm{k}_{1}=\mathrm{h}_{\mathrm{t}} \mathrm{l}_{\alpha}\left(\mathrm{t}, \mathrm{y}_{1 \alpha}(\mathrm{t}), \mathrm{y}_{2 \alpha}(\mathrm{t})\right), \mathrm{l}_{1}=\mathrm{h}_{\mathrm{t}} \mathrm{k}_{\alpha}\left(\mathrm{t}, \mathrm{y}_{1 \alpha}(\mathrm{t}), \mathrm{y}_{2 \alpha}(\mathrm{t})\right)$.

11. $\mathrm{k}_{2}=\mathrm{h}_{\mathrm{t}} \mathrm{l}_{\alpha}\left(\mathrm{t}+\mathrm{h}_{\mathrm{t}}, \mathrm{y}_{1 \alpha}(\mathrm{t})+\mathrm{k}_{1}, \mathrm{y}_{2 \alpha}(\mathrm{t})+\mathrm{l}_{1}\right), \mathrm{l}_{2}=\mathrm{h}_{\mathrm{t}} \mathrm{k}_{\alpha}\left(\mathrm{t}+\mathrm{h}_{\mathrm{t}}, \mathrm{y}_{1 \alpha}(\mathrm{t})+\mathrm{k}_{1}, \mathrm{y}_{2 \alpha}(\mathrm{t})+\mathrm{l}_{1}\right)$

12. $\mathrm{y}_{1 \alpha}\left(\mathrm{t}+\mathrm{h}_{\mathrm{t}}\right)=\mathrm{y}_{1 \alpha}(\mathrm{t})+\frac{1}{2}\left(\mathrm{k}_{1}+\mathrm{k}_{2}\right), \mathrm{y}_{2 \alpha}\left(\mathrm{t}+\mathrm{h}_{\mathrm{t}}\right)=\mathrm{y}_{2 \alpha}(\mathrm{t})+\frac{1}{2}\left(\mathrm{l}_{1}+\mathrm{l}_{2}\right)$.

\section{Numerical Example}

Let us consider the nonlinear fuzzy problem,

$$
\left\{\begin{array}{l}
X^{\prime}(t)=t^{2} X(t)-4 t X(t)+3 X(t) \quad t \in[0,2] \\
X(0)=(0,1,1)
\end{array}\right.
$$

Approximation solution of Example 1, for $\mathrm{t}=0,0.02,0.04,0.06$ are tabulated in Table 1:

Table 1: Approximation solution of Example 1

\begin{tabular}{|c|c|c|c|c|}
\hline$\alpha$ & $\mathrm{t}=0$ & $\mathrm{t}=0.02$ & $\mathrm{t}=0.04$ & $\mathrm{t}=0.06$ \\
\hline 0 & {$[-1.0,1.0]$} & {$[-1.0627,1.0627]$} & {$[-1.1292,1.1292]$} & {$[-1.2000,1.2000]$} \\
\hline 0.1 & {$[-0.9,0.9]$} & {$[-0.9564,0.9564]$} & {$[-1.0163,1.0163]$} & {$[-1.0800,1.0800]$} \\
\hline 0.2 & {$[-0.8,0.8]$} & {$[-0.8501,0.8501]$} & {$[-0.9034,0.9034]$} & {$[-0.9600,0.9600]$} \\
\hline 0.3 & {$[-0.7,0.7]$} & {$[-0.7439,0.7439]$} & {$[-0.7905,0.7905]$} & {$[-0.8400,0.8400]$} \\
\hline 0.4 & {$[-0.6,0.6]$} & {$[-0.6376,0.6376]$} & {$[-0.6775,0.6775]$} & {$[-0.7200,0.7200]$} \\
\hline 0.5 & {$[-0.5,0.5]$} & {$[-0.5313,0.5313]$} & {$[-0.5646,0.5646]$} & {$[-0.6000,0.6000]$} \\
\hline 0.6 & {$[-0.4,0.4]$} & {$[-0.4251,0.4251]$} & {$[-0.4517,0.4517]$} & {$[-0.4800,0.4800]$} \\
\hline 0.7 & {$[-0.3,0.3]$} & {$[-0.3188,0.3188]$} & {$[-0.3388,0.3388]$} & {$[-0.3600,0.3600]$} \\
\hline 0.8 & {$[-0.2,0.2]$} & {$[-0.2125,0.2125]$} & {$[-0.2258,0.2258]$} & {$[-0.2400,0.2400]$} \\
\hline 0.9 & {$[-0.1,0.1]$} & {$[-0.1063,0.1063]$} & {$[-0.1129,0.1129]$} & {$[-0.1200,0.1200]$} \\
\hline 1 & {$[0.0,0.0]$} & {$[0.0,0.0]$} & {$[0.0,0.0]$} & {$[0.0,0.0]$} \\
\hline
\end{tabular}




\section{Rostami, M. Kianpour, E. bashardoust/ TJMCS Vol .2 No.4 (2011) 667-671}

\section{Conclusion}

In this paper we present some results on fuzzy differential equation with generalized derivative. Also, we obtain new method for solving the differential equations that are not strictly increasing or strictly decreasing.

\section{References}

[1] DP. Datta, the golden mean, scale free extension of real number system, fuzzy sets and $1 / \mathrm{f}$ spectrum in physics and biology, Chaos solitons and Fractals 17 (2003) 781-8.

[2] Ms. El Naschie, From experimental quantum optics to quantum gravity via a fuzzy Kahler manifold, Chaos solitons and Fractals 25 (2005) 969-77.

[3] M. Puri, D. Ralescu, Differential and fuzzy functions, J Math Anal Appl 91 (1983) 552-8.

[4] B. Bede, SG .Gal, almost periodic fuzzy-number-valued functions. Fuzzy Sets and Systems 147 (2004) 385-403.

[5] B. Bede, SG .Gal, Generalizations of the differentiability of fuzzy-number-valued functions with applications to fuzzy differential Equations, Fuzzy Sets and Systems 151 (2005) 581-99.

[6] Y. Chalco-Cano, H. Roman-Flores, on new solutions of fuzzy differential equations, Chaos Solitons and Fractals 38 (2006) 112-119.

[7] Y. Chalco-Cano, H. Roman-Flores, Comparation between some approaches to solve fuzzy differential equations, Fuzzy Sets and Systems 160 (2009) 1517-1527.

[8] Y. Chalco-Cano, H. Roman-Flores, M.A. Rojas-Medar, fuzzy differential equation with generalized derivative, in : Proc.27th NAFIPS Internet.Conf.IEEE, 2008.

[9] Y.J. Cho, H.Y. Lan, The existence of solution for the nonlinear first order fuzzy differential equations with iscontinuous conditions, Dynamics Continuous Discrete Inpulsive Systems Ser.A Math.Anal. 14 (2007) 873-884.

[10] P. Diamond, Brief note on the variation of constants formula for fuzzy differential equations, Fuzzy Set Syst 129 (2002) 65-71.

[12] O. Kaleva, Fuzzy differential equations, Fuzzy Sets and Systems 24 (1987) 301-17.

[13] O. Kaleva, A note on fuzzy differential equations, Nonlinear Analysis 64 (2006) 895-900.

[14] V. lakshmikantham, R.N. Mohapatra, theory of fuzzy differential equation and inclusions, Taylor and Francis, London, 2003.

[18] J.J. Niteo, R. Rodriguez-Lopez, D.franco, linear first-order fuzzy differential equation, internet.J.Uncertainty Fuzziness Knowledge-Based Systems 14 (2006) 687-709.

[21] S. Abbasbandy, T.A. Viranloo, LoPEz-Pouso, J.J. Niteo, Numerical Methods for Fuzzy Differential Inclusions, Computers and Mathematics with Applications 48 (2004) 1633-1641.

[22] James J. Buckley, Thomas Feuring, Fuzzy differential equations, Fuzzy Sets and Systems 110(2000) 43-54.

[23] S. Abbasbandy, Juan J. Nieto, M. Alavi, Tuning of reachable set in one dimensional fuzzy differential inclusions, Chaos Solitons and Fractals 26 (2005) 1337-1341. 